\title{
Drivers of COVID-19 vaccinations: vaccine delivery and delivery efficiency in the United States
}

\author{
Rajeev K. Goel ${ }^{1,2}$ (1) $\cdot$ Michael A. Nelson ${ }^{3}$ (1)
}

Accepted: 4 May 2021 / Published online: 17 June 2021

(C) The Author(s), under exclusive licence to Springer Science+Business Media, LLC, part of Springer Nature 2021

\begin{abstract}
This paper adds some formal research to the success of ongoing efforts to combat the COVID-19 pandemic by examining the drivers of the administration and delivery efficiency of coronavirus vaccines. For this purpose, we use data from the 50 US states and place the formal analysis in the context of socio-economic drivers of vaccinations. Results show that state-economic prosperity and rural population aid vaccine administration and delivery efficiency. Delivery efficiency improves in states with more nursing homes per capita, in states with more COVID-19 deaths, and with more health workers. A subset of health workers, including physicians and nurses, did not significantly impact administration or efficiency. On the other hand, vaccination efficiency was lower in states with a centralized public health agency. States with a larger share of the elderly population and those with Democrats as governors were no different from others with regard to vaccinations. Robustness checks are performed using vaccination data from a more recent period. Finally, a state's legacy of corrupt activity, across two different time dimensions, is broadly consistent with the greasing effects of corruption. Some policy implications based on the evolving data are discussed.
\end{abstract}

Keywords COVID-19 $\cdot$ Coronavirus $\cdot$ Vaccine $\cdot$ Efficiency $\cdot$ Rural $\cdot$ Deaths $\cdot$ Health workers $\cdot$ Corruption $\cdot$ Networking $\cdot$ United States

JEL classification $\mathrm{H} 5 \cdot \mathrm{H} 75 \cdot \mathrm{I} 10 \cdot \mathrm{I} 18 \cdot \mathrm{K} 42$

Useful comments by the Editor, referees, and Viraat Goel are appreciated. An earlier version of this paper was circulated as a CESifo working paper \#8972.

Rajeev K. Goel

rkgoel@ilstu.edu

1 Department of Economics, Illinois State University, Normal, IL 61790-4200, USA

2 Kiel Institute for the World Economy, Kiel, Germany

3 University of Akron, Akron, OH, USA 


\section{Introduction}

The recent rollouts of coronavirus vaccines in many nations (and some others in development), coupled with the increasing infection cases/deaths from the disease, has added public- and political pressures to the expedited and widespread dissemination of the vaccines. Even the business sector has recently become concerned with sluggish vaccine rollout due to adverse implications for the speed of economic recovery. ${ }^{1}$ This heightened interest has resulted in greater scrutiny of the rollout process, with some initial reports of inefficiency and mismanagement emerging. ${ }^{2}$

Some nations have been better than others in vaccinating their populations; for example, Israel's dexterity in vaccinating its population has received positive reviews. ${ }^{3}$ While the institutional, economic, and geo-political factors vary substantially across nations, (and they might explain key reasons behind vaccination differences), ${ }^{4}$ it is more surprising, even troubling, when subnational governments within a union exhibit substantial differences in vaccine rollouts. In the US, some states have been much better than others at vaccinating their populations, while others have lagged, sometimes due to no apparent reasons. ${ }^{5}$ Some reports have sensed a lack of transparency behind a failure to understand differences in vaccinations across jurisdictions. ${ }^{6}$ However, before any corrective policy measures can be undertaken, a good understanding of the factors driving vaccinations across US states is essential. It is towards that goal this paper is focused.

Although new information about vaccination efficiency and coverage is literally emerging every day, it seems useful, both from an academic and a policy perspective, to analyze the available information in terms of the identification of bottlenecks in vaccinations. What are the significant factors driving the delivery of vaccines? Are the determinants of vaccine delivery different from the drivers of vaccine delivery efficiency?

In this respect, we examine both the dissemination or diffusion of vaccines (vaccines actually administered) and the efficiency in their delivery (what percentage of vaccines that a state received were actually administered) during the early stages of the vaccine rollout in the US. Given the gravity of the underlying health and economic consequences surrounding the pandemic, the speed and spread of vaccinations are of paramount importance both to the public and the policymakers. An identification of significant factors facilitating vaccinations and promoting the efficiency of vaccinations would be useful information not only for jurisdictions where vaccinations are underway but also in areas that are looking to start vaccinating their populations. Some literature on the economic aspects of the pandemic has emerged, examining various aspects (see,

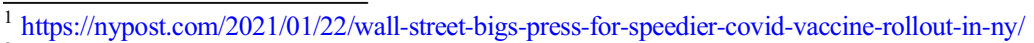

${ }^{2}$ https://www.msn.com/en-us/news/world/angry-eu-looks-to-restrict-vaccine-exports-as-supply-shortage-hitsslow-rollout/ar-BB1d6Upt; https://www.nytimes.com/2021/01/05/opinion/letters/covid-vaccinations.html

${ }^{3} \mathrm{https}: / /$ www.cbc.ca/news/world/israel-covid-vaccinations- 1.5859396

${ }^{4}$ For example, using cross-country data, Goel et al. [10] show how corruption impacts dimensions of supply chain differently.

${ }^{5}$ See, for examples, https://www.stltoday.com/news/local/govt-and-politics/west-virginia-touts-covid-19vaccination-success-story-as-national-rollout-sputters/article_b68f9b1a-1 feb-5d88-a460-52f2927a0034.html; https://philadelphia.cbslocal.com/video/5234110-gov-tom-wolf-blaming-federal-government-for-slow-covid19-vaccine-rollout-in-pennsylvania/

${ }^{6} \mathrm{https}$ ://news.sky.com/story/covid-19-success-of-vaccine-rollout-will-remain-a-mystery-so-long-asgovernment-keeps-key-data-under-wraps-12186846
} 
for examples, Alfano and Ercolano [1], Asongu et al. [2], Baldwin and Weder di Mauro [3], Farzanegan et al. [7], Goel et al. [10], Goel and Nelson [12], Persad et al. [15], Price and van Holm [17], Roccato et al. [18], Salvatore et al. [19]).

This paper adds initial formal research to the success of ongoing efforts to combat the COVID-19 pandemic by examining the drivers of the administration and delivery efficiency of coronavirus vaccines in the early stages of the vaccination campaign in the US. For this purpose, we use data from the 50 US states and place the formal analysis in the context of socio-economic drivers of vaccinations. Results show that state-economic prosperity and rural population aid both vaccine administration and delivery efficiency. Furthermore, more populous states have a weaker record for both outcome measures, at least in the early stages of the vaccine rollout campaign. Delivery efficiency improves in states with more nursing homes per capita, in states with more COVID-19 deaths, and those with more health workers. On the other hand, vaccination efficiency was lower in states with a centralized public health agency. States with a larger share of the elderly population and those with Democrats as governors were no different from others with regard to vaccinations. Finally, a state's legacy of corrupt activity is broadly consistent with the greasing effects of corruption in improving vaccine administration and delivery efficiency. Some policy implications based on the evolving data are discussed in the concluding remarks.

The structure of the rest of the paper includes the model in the next section, followed by data and estimation, results, and conclusions.

\section{Model}

To study the drivers of vaccinations and vaccination efficiency, we start with a simple linear model, that accounts for cross-state economic, political, social, and medical differences. With the unit of observation at the state level, the estimated equations, with alternative dependent variables, take the following general forms

VACadmin $=\mathrm{f}\left(\right.$ Healthcare market $_{\mathrm{j}}, \mathrm{Z}$, Corruption $)$

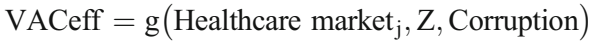

$$
\begin{aligned}
& \mathrm{j}=\text { PHYSICIANS, NURSES, HEALTHworkers, CENTRALIZED, SlhHOSP, nHOMES } \\
& \mathrm{Z}=\text { RGDPpc, RURAL, POP, 65plus, cDEATHS, Governor }
\end{aligned}
$$

The two dependent variables capture qualitatively different aspects of the vaccine delivery process: (i) VACadmin captures the dissemination of vaccinations; and (ii) VACeff denotes the related efficiency - the percentage of vaccines that a state received that were actually administered. VACadmin would be related to supply shortages, administrative bottlenecks and supply chain issues (see Goel [9], Goel et al. [10]), while VACeff would be primarily limited by internal bottlenecks. Viewed alternatively, our consideration of the two dimensions of vaccinations can be seen as addressing external versus internal bottlenecks, respectively. 
The correlation between VACadmin and VACeff in our sample is 0.84 for the January 12, 2021 date considered below and 0.64 for the latter, February 2, 2021, date.

RGDPpc captures economic prosperity in a state, with more prosperous states having a better infrastructure that would aid the administration and efficiency of vaccinations. The effect of rural populations (RURAL) could go either way. On the one hand, a greater rural population would face challenges in accessing medical facilities (reducing vaccinations); on the other hand, informal social and communications networks might be stronger in rural areas that might aid in the dissemination of information in accessing vaccinations. Greater elderly populations (65plus) would facilitate vaccinations as many states have initially prioritized the vaccinations of elderly residents. Further, the size of a state (in terms of the state population (POP)), could impact vaccinations. One could envision scenarios where smaller states might have coordination or networking advantages at least in the initial vaccination stages. In our sample, a little over a quarter of the population resided in rural areas, and about $17 \%$ of the population in a state on average was above the age of 65 (Table 1).

Coronavirus deaths (cDEATHS) would also add a sense of urgency to vaccinations in a state, ceteris paribus. Conversely, some states with high death rates might rather direct some resources to curb mortality rates than on preventing infections. As of January 14, 2021, the average COVID-19 related deaths per 100,000 state residents were about 112 .

All these aspects, however, are subject to the political climate in a state. Depending upon the political inclinations of the chief executive of a state, the response to combating COVID-19 might be different (British Medical Journal [5], Chabner [6]). Accordingly, we include a dummy variable, Governor, to denote states with a governor belonging to the Democratic party (see Potrafke [16] for a broader discussion of the role of the political variables; also see Bartolini and Santolini [4]). In our sample, $46 \%$ of the states had a Democrat as governor in 2021.

Later in the paper (Section 4.4), we consider the possible influence of a state's legacy of corruption, using two alternative measures: (a) a five-year average of federal corruption convictions by state (per capita), CorruptSR; and (b) a corresponding tenyear average of corruption convictions, CorruptLR. ${ }^{7}$ Corrupt activity is variable across states in the United States, with convictions showing some lumpiness in specific years. The averaging over time smooths some of the large variations and the longer-term considered would also better account for changes in political regimes, in cases certain regimes are more closely associated with corrupt activity.

Corruption can proxy for institutional weakness and can potentially have a "greasing"or a "sanding" effect on vaccinations, with possible variations in the administration and efficiency of vaccinations. A legacy of corruption would grease vaccination drives when some intrusive regulations may be bypassed to deliver vaccinations (by health providers or supply chain participants), yet states with high corruption activity might impose a greater transaction cost, slowing down or sanding vaccination drives.

Finally, and perhaps most pertinent to the issue at hand, the role of the medical establishment in a state would crucially influence the delivery and efficiency of vaccinations. In this regard, we consider a number of dimensions: (i) the number of physicians per capita

\footnotetext{
${ }^{7}$ Corruption convictions have been widely used in the literature to capture state-level corruption in the United States (see, for examples, Glaeser and Saks [8], Goel and Nelson [11]).
} 
Table 1 Variable definitions, summary statistics and data sources

\begin{tabular}{lll}
\hline Variable & $\begin{array}{l}\text { Mean } \\
\text { (standard deviation) }\end{array}$ \\
\hline
\end{tabular}

Vaccine administration: COVID-19 vaccinations administered, per 100 thou- as of Jan. 12, 2021 $\begin{array}{ll}\text { sand state population. [VACadmin] } & 3007.6(1014.0)\end{array}$

as of Feb. 2, 2021

9934.6 (1818.6)

Vaccine administration efficiency: Percentage of distributed COVID-19 vac- as of Jan 12, 2021 cinations that were administered. [VACeff] 36.9 (11.9)

as of Feb. 2, 2021

$64.5(7.3)$

Real GDP per capita - 2019 (chained 2012 dollars, in thousands). [RGDPpc] 54.5

State population - 2019 (per 100 thousand, in natural logs). [POP] 3.69

Percentage of population classified as rural, 2010. [RURAL] 26.4

Percentage of population over 65 years old, 2019. [65plus] 17.0

(1.9)

Democrat governor, January 2021. $(1=$ yes, $0=$ no). [Governor] 0.46

COVID-19 total deaths per 100 thousand population (Jan. 14, 2021). 112.5 [cDEATHS]

Number of active RN licenses per 100 thousand population, 2021. [NURSES] 1723.8

Professionally active physicians per 100 thousand population, 2020. 299.4 [PHYSICIANS]

State and local government spending on health and hospitals, fiscal year 2018, 809.1 $\$$ per capita. [SlhHOSP]

Centralized state public health agency, 2011. $(1=$ yes; $0=$ no $)$. [CENTRALIZED]

Nursing homes per 100 thousand population, 2016. [nHOMES]

Workers in health care occupations per 100 thousand population, 2019 . $\quad 4670.3$ [HEALTHworkers]

Corruption, short-term: Average corruption convictions per 100 thousand

All data are by state

Sources:

[1] Centers for Disease Control and Prevention, https://covid.cdc.gov/covid-data-tracker/\#vaccinations

[2] US Bureau of Economic Analysis, https://www.bea.gov/

[3] Statistical Abstract of the United States, 2015.

[4] US Census Bureau, https:/www.census.gov/data/datasets/time-series/demo/popest/2010s-state-detail. html\#par_textimage_2063038847

[5] https://en.wikipedia.org/wiki/List_of_current_United_States_governors 
[6] The COVID Tracking Project, https://covidtracking.com/data

[7] NCSBN, https://www.ncsbn.org/6161.htm

[8] Kaiser Family Foundation, https://www.kff.org/other/state-indicator/total-active-physicians/? currentTimeframe $=0 \&$ sortModel $=\% 7 \mathrm{~B} \% 22$ colld $\% 22: \% 22$ Location $\% 22$

[9] U.S. Census, Annual Survey of State and Local Government Finances, https://www.census.gov/programssurveys/gov-finances.html

[10] Association of State and Territorial Health Officials, 2012. State Public Health Agency Classification: Understanding the Relationship Between State and Local Public Health. Arlington, VA.

[11] U.S. National Center for Health Statistics, Health, United States, 2017, September 2018. https://www.cdc. gov/nchs/hus/contents2017.htm\#Table

[12] Bureau of Labor Statistics, Occupational Employment Statistics Survey, May 2019. Occupation Codes 29-0000 and 31-0000

[13] U.S. Department of Justice, https://www.justice.gov/criminal/pin, January 2021

(PHYSICIANS); (ii) registered nurses per capita (NURSES); (iii) more broadly, the number of health workers per capita in a state (HEALTHworkers); (iv) the number of nursing homes per capita (nHOMES); (v) a measure, CENTRALIZED, capturing whether a state's public health system was centralized; and (vi) a measure accounting for the fiscal decentralization in health spending by including SlhHOSP to capture state and local government spending on health and hospitals. On average, there were about six nursing homes per 100,000 state population, and $40 \%$ of the states had a centralized public health agency.

We would expect more medical personnel to aid vaccinations, ceteris paribus, although this would partly depend upon the prevalence of other diseases in the state, and the contractual obligations in different states. More nursing homes, at least in the initial vaccine rollout stages where nursing home residents are prioritized, could be expected to result in greater vaccinations in a state, ceteris paribus. State and local spending on health signifies government participation in health at the local level. On the one hand, this signals greater state capacity to undertake vaccinations; on the other hand, greater health spending might capture commitments elsewhere (institutional inertia) that might slow or inhibit the rapid transition to vaccinations. Finally, the degree of centralization of the health agency captures decision-making, coordination, and red-tape aspects (see Turnbull and Djoundourian [20]).

We turn next to a discussion of the data employed and the estimation strategy used.

\section{Data and estimation}

\subsection{Data}

Data on COVID-19 vaccine doses distributed to the states and the number of doses administered are taken from the US Centers for Disease Control and Prevention (CDC) COVID Tracker website. These data are updated daily by the CDC and two different dates were selected for analysis. State-level tracking began on December 14, 2020, about the time initial vaccine shipments began to roll out to the states. While states were given some guidance from the $\mathrm{CDC}$, it was up to the individual states to develop their own distribution plan and prioritization guidelines for who would receive the vaccine. Further, in states with decentralized health care systems, vaccine rollout decisions and 
implementation plans were often left to local officials. Even in mid-January 2021, statelocal distribution plans were still fluid in many jurisdictions, with timelines and priority group designations varying widely across the states. Based on this, we chose admittedly somewhat arbitrarily - state-level outcomes as of January 12, 2021, as the first date of analysis. Even by this date, most states were still vaccinating the Phasela priority group, generally consisting of health care workers and long-term care residents and staff. ${ }^{8}$

The upper-left chart of Fig. 1 provides a visual display of the differences among the states in vaccine distribution as of the January 12, 2021 data. The top ten states are shown at the top, depicted in navy blue while the ten states with the lowest number of vaccines administered are shown in dark green. As of that date, the mean number of vaccinations per 100,000 population [VACadmin] was 3008, with a wide range from 1355 (Arkansas) to 5766 (West Virginia). Similarly, the upper-right chart of the figure shows state differences in their record of vaccination efficiency. The mean state vaccination rate [VACeff] stood at 37\%, with a low of $15 \%$ (Arkansas) to a high of $74 \%$ (North Dakota).

To gain additional insights into the state records as they gained more experience with vaccine rollouts, the date of February 2, 2021 was also separately analyzed. By this date, most states had advanced to the Phase $1 \mathrm{~b}$ priority group, with those that followed the CDC Advisory Committee on Immunization Practices (ACIP) recommendations now vaccinating persons 75 years and older. ${ }^{9}$ A few states had even progressed to Priority group 1c. All states included some seniors in the eligibility group, although the minimum age varied from 65 years old to 75 depending upon the state. ${ }^{10}$ The bottom two charts show the differences among the states with respect to the two outcome measures considered in the analysis. The mean state vaccination rate by that date rose to $65 \%$, while the average number of vaccinations per 100 thousand population [VACadmin] stood at 9934, also showing a wide range from 7087 (Idaho) to 16,874 (Alaska).

Data on state-level COVID-19-related deaths (confirmed or probable) [cDEATHS] are drawn from The COVID Tracking Project and are based on the cumulative outcomes as of January 14, 2021. Mean death rates per 100 thousand population stood at 112.5, a figure that masks a wide variation among the states, where the death toll was only 22 in Hawaii while New Jersey had a high of 228.

State capacity to conduct the vaccine rollout is measured by per capita state and local government spending on health and hospitals (current expenditure only) for the fiscal year 2018 [SlhHOSP]. ${ }^{11}$ Along another related dimension, the classification of the

\footnotetext{
${ }^{8}$ Four states added seniors to the Phase 1a eligibility groups, including Georgia and Florida (65 and older), Tennessee (75+), and West Virginia (80+). By January 11, 2021, 13 other states and the District of Columbia either had or were transitioning to Phase2a, and made some older senior age groups eligible for the vaccine. https://www.kff.org/coronavirus-covid-19/issue-brief/the-covid-19-vaccination-line-an-update-on-stateprioritization-plans/

${ }_{9} \mathrm{https} / /$ www.cdc.gov/vaccines/hcp/acip-recs/vacc-specific/covid-19.html

${ }^{10} \mathrm{https} / /$ www.kff.org/other/state-indicator/state-covid-19-vaccine-priority-populations/?currentTimeframe= $0 \&$ print $=$ true \&sortModel $=\% 7 \mathrm{~B} \% 22$ colId $\% 22: \% 22$ Location $\% 22, \% 22$ sort $\% 22: \% 22$ asc $\% 22 \% 7 \mathrm{D} \#$ In an analysis not reported below to conserve space, a variable representing the minimum age group eligible for vaccinations at each point in time [Age_Priority] was also included in each model. The inclusion of this variable did not materially affect any of the conclusions drawn below regarding the other variables in the model. These results are reported in Table A1 in the Appendix.

${ }^{11}$ Ideally, a more narrowly-based measure would have been preferred as the Census Bureau lumps together all forms of spending on public health in the data it reports, including activities such as animal control and inspections of food handling establishments that are not directly relevant in the current context.
} 
Vaccines Administered - January 12, 2021

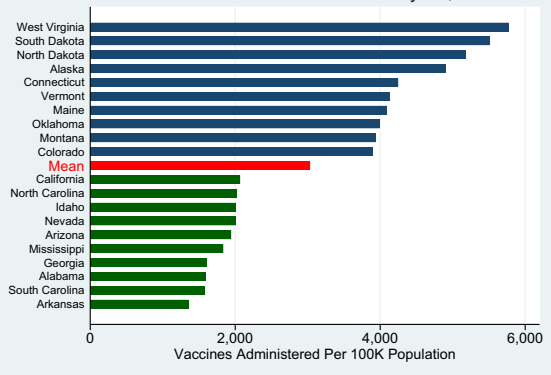

Vaccines Administered - February 2, 2021

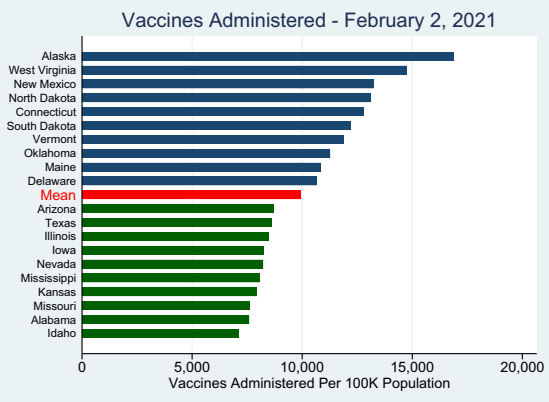

Vaccines Efficiency - January 12, 2021

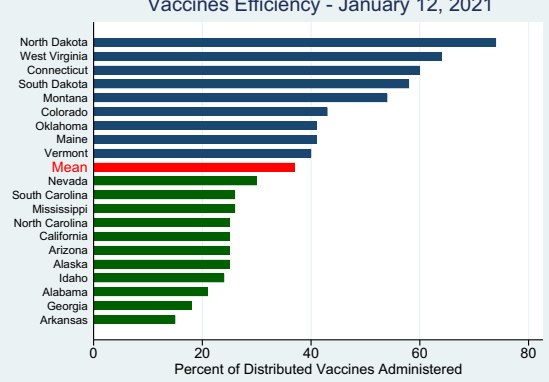

Vaccines Efficiency - February 2, 2021

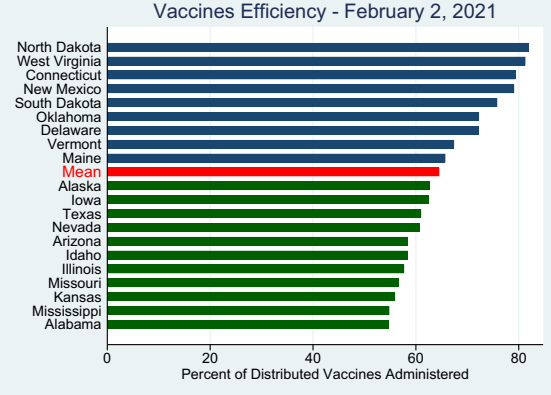

Fig. 1 Vaccines Administered and Vaccines Efficiency: Top Ten and Bottom Ten US States

organizational structure of state and local public health agencies with respect to their functional and administrative relationships is based on an analysis undertaken by the Association of State and Territorial Health Officials in 2011. In that analysis, states with no local health units were classified as centralized [CENTRALIZED $=1$ ] as were states where the local units are led by state employees. States where the local public health units were led by local employees were classified as decentralized [CENTRALIZED $=0$ ]. Based on their classification criteria, 32 states had decentralized public health systems in 2011 while the other 18 were centralized. ${ }^{12}$

Further details of all of the other variables used in the analysis, descriptive statistics, and data sources can be found in Table 1.

\subsection{Estimation}

For the vaccinations administered [VACadmin] an outcome measure model, estimation is carried out using Ordinary Least Squares (OLS) with robust standard errors. Regarding the vaccination delivery efficiency outcome measure [VACeff], its value lies within the $[0,1]$ interval when expressed as a fraction. An OLS regression in this case suffers from similar problems to linear probability models involving binary response-dependent variables. In particular, predicted probabilities can lie outside the $[0,1]$ interval

\footnotetext{
${ }^{12}$ In a preliminary analysis, decentralization of state public health care was alternatively measured as the local government share of total state-local government spending on health and hospitals [DeCENTRALIZED]. The results (reported in the Appendix, Table A1 - see supplementary materials) are qualitatively similar to what is reported below using the centralization [CENTRALIZED] classification variable.
} 
and linear relationships with the independent variables in the model are assumed. To address this, we follow Papke and Wooldridge [14] and Wooldridge [22] when using VACeff-dependent variables and fit a fractional response model using the quasilikelihood estimator, under the assumption that the distribution of the conditional mean of the response variable follows a logistic functional form.

\section{Results}

We alternatively discuss results with our two dependent variables: VACadmin and VACeff, respectively.

\subsection{Drivers of dissemination of vaccines (VACadmin)}

Table 2 reports results with VACadmin as the dependent variable during the very early stages of the vaccine rollout. In the data as of January 12, 2021, a little over 3000 persons per 100,000 population were vaccinated on average. The related results are reported in Table 2 with four different modeling variations.

The results show that more prosperous states and states with greater rural populations had greater vaccine administrations. The resulting coefficients are statistically significant in all the models estimated. In terms of relative magnitudes, the elasticity of VACadmin with respect to RGDPpc turns out to be 0.8 , while that with respect to RURAL is about a fourth of that at $0.2 .{ }^{13}$ From a policy perspective, of course, changing the composition of the rural population is very slow, time-consuming, and often politically challenging. Furthermore, smaller states (POP) seem to be more adept at vaccinating their populations, consistent with the notion of a relatively better coordination, networking, and communication in such states.

When medical personnel are considered in Models 1.2 and 1.4, we see that the coefficients on PHYSICIANS and NURSES are statistically insignificant, whereas that on the broader measure, HEALTHworkers, is positive and significant (at the $10 \%$ level). This finding alludes to the importance of other health workers - e.g., appointment schedulers, nursing assistants, etc. These resources are especially important in the context of COVID vaccinations with inherent short shelf-life, scarcity, and refrigeration/transportation requirements. In addition, states with more nursing homes were no different from others in vaccine administration.

Turning to structural issues with respect to governmental involvement in the health system of states, states with a centralized health system were no different from others with regard to vaccinations. Surprisingly, state and local governments spending greater amounts on health and hospitals tended to have lower vaccine administrations. ${ }^{14}$ This finding can be viewed in the context of a greater government size (involvement) leading to some decision-making lethargy or to a lack of coordination between federal

\footnotetext{
${ }^{13}$ Elasticities are calculated based on the respective sample means.

${ }^{14}$ It is also important to acknowledge, however, that the measure of health spending used here encapsulated spending on public health in other areas not directly relevant to the administration of the vaccine to the population (see Footnote 11).
} 
Table 2 Drivers of COVID-19 Vaccinations Administration (Jan. 12, 2021). Outcome measure: Vaccines Administered per 100k population [VACadmin]

\begin{tabular}{|c|c|c|c|c|}
\hline Model $\rightarrow$ & 1.1 & 1.2 & 1.3 & 1.4 \\
\hline $\begin{array}{l}\text { Real GDP per capita } \\
\text { [RGDPpc] }\end{array}$ & $\begin{array}{l}42.61^{* *} \\
(3.2)\end{array}$ & $\begin{array}{l}33.38^{* *} \\
(2.1)\end{array}$ & $\begin{array}{l}44.23^{* *} \\
(3.8)\end{array}$ & $\begin{array}{l}25.92^{*} \\
(1.7)\end{array}$ \\
\hline $\begin{array}{l}\text { State population } \\
{[\mathrm{POP}]}\end{array}$ & $\begin{array}{l}-353.49^{* *} \\
(2.6)\end{array}$ & $\begin{array}{l}-335.57^{* *} \\
(2.0)\end{array}$ & $\begin{array}{l}-323.05^{* *} \\
(2.3)\end{array}$ & $\begin{array}{l}-377.63^{* *} \\
(3.1)\end{array}$ \\
\hline $\begin{array}{l}\text { Rural population } \\
\text { [RURAL] }\end{array}$ & $\begin{array}{l}22.58^{* * *} \\
(2.2)\end{array}$ & $\begin{array}{l}20.83^{*} \\
(1.9)\end{array}$ & $\begin{array}{l}25.14^{* *} \\
(2.2)\end{array}$ & $\begin{array}{l}12.07 \\
(1.1)\end{array}$ \\
\hline $\begin{array}{l}\text { Population over } 65 \\
\text { [65plus] }\end{array}$ & $\begin{array}{l}42.32 \\
(0.5)\end{array}$ & $\begin{array}{l}-2.50 \\
(0.0)\end{array}$ & $\begin{array}{l}41.86 \\
(0.5)\end{array}$ & $\begin{array}{l}-7.91 \\
(0.1)\end{array}$ \\
\hline $\begin{array}{l}\text { Democrat Governor } \\
\text { [Governor] }\end{array}$ & $\begin{array}{l}-161.35 \\
(0.7)\end{array}$ & $\begin{array}{l}-174.21 \\
(0.7)\end{array}$ & $\begin{array}{l}-138.94 \\
(0.6)\end{array}$ & $\begin{array}{l}-247.51 \\
(1.0)\end{array}$ \\
\hline $\begin{array}{l}\text { COVID-19 deaths } \\
\text { [cDEATHS)] }\end{array}$ & $\begin{array}{l}1.87 \\
(0.8)\end{array}$ & $\begin{array}{l}1.11 \\
(0.4)\end{array}$ & $\begin{array}{l}0.26 \\
(0.1)\end{array}$ & $\begin{array}{l}-0.21 \\
(0.1)\end{array}$ \\
\hline $\begin{array}{l}\text { Registered nurses } \\
\text { [NURSES] }\end{array}$ & & $\begin{array}{l}0.25 \\
(0.5)\end{array}$ & & \\
\hline $\begin{array}{l}\text { Physicians } \\
\text { [PHYSICIANS] }\end{array}$ & & $\begin{array}{l}1.45 \\
(0.6)\end{array}$ & & \\
\hline State spending on health and hospitals [SlhHOSP] & & & $\begin{array}{l}-0.78^{* * *} \\
(5.3)\end{array}$ & \\
\hline Centralized public health [CENTRALIZED] & & & $\begin{array}{l}-411.62 \\
(1.3)\end{array}$ & \\
\hline $\begin{array}{l}\text { Nursing homes } \\
\text { [nHOMES] }\end{array}$ & & & $\begin{array}{l}34.73 \\
(0.8)\end{array}$ & \\
\hline $\begin{array}{l}\text { Health care workers } \\
\text { [HEALTHworkers] }\end{array}$ & & & & $\begin{array}{l}0.40^{*} \\
(1.8)\end{array}$ \\
\hline Observations & 50 & 49 & 50 & 50 \\
\hline F-statistic & $3.98^{* *}$ & $4.19^{* *}$ & $7.67^{* *}$ & $5.17^{* *}$ \\
\hline R-square & 0.39 & 0.41 & 0.58 & 0.43 \\
\hline
\end{tabular}

See Table 1 for variable details. All models include a constant term and are estimated via ordinary least squares with robust standard errors. The numbers in parentheses are (absolute value) t-statistics. Vaccine administered data are for January 12, 2021

* denotes statistical significance at the $10 \%$-level, and ** denotes significance at the $5 \%$-level (or better)

and local governments - especially relevant in the context of COVID-19 vaccines (e.g., transportation, logistics, execution, etc.).

With regard to the other controls, states with Democrats as governors, those with more elderly populations, with relatively greater COVID-19 death rates, more nursing homes, and with more health workers were no different from others when it came to administering vaccines. ${ }^{15}$

Later, in Section 4.3, we shall examine how these results change as the initial vaccination period has elapsed, along with a change in government leadership at the federal level. We turn next to examining the determinants of vaccine efficiency.

\footnotetext{
${ }^{15}$ The insignificance of the Governor may be seen in the context of the structural inability or political unwillingness of states' chief executives to appreciably steer vaccination policy in certain directions.
} 


\subsection{Drivers of vaccine administration efficiency (VACeff)}

The results with VACeff as the dependent variable using January 12, 2021 data are reported in Table 3. The average percent of vaccines that were delivered over what was received in each state was about $37 \%$ (Table 1). Vaccine efficiency is especially relevant in the case of the COVID-19 vaccines, not only to save lives but also to conserve and prevent a scarce resource from going waste (because unused vaccines that have been on the shelf for a while lose their efficacy).

The results for vaccine efficiency provide some interesting contrasts with those with vaccine administration. More prosperous states again had some comparative advantages in administering efficiency; however, the coefficient on RGDPpc was statistically significant in two of the four models estimated. On the other hand, vaccination efficiency was no different in more rural states and the administration advantages of smaller states were largely absent when it came to efficiency - the coefficient on POP was negative and marginally significant in Model 2.4.

More significant differences in administration and efficiency emerge with respect to the impact of COVID-19-related deaths. States with a greater number of deaths had greater vaccination efficiency. It may be the case that states with more deaths also had more hospitalization, enabling better and faster alternative uses of unused vaccines or it may have to do with the politics of expedited vaccinations in states facing adverse press reports with more deaths.

Again, as in Table 2, vaccination efficiency was greater in states with more health workers, but not just with more nurses and physicians. On the other hand, both structural centralization of state health systems (CENTRALIZED) and fiscal decentralization tended to undermine efficiency.

Efficiency was, however, higher in states with more nursing homes, in the early phases of the vaccine rollout. Whether this is still the case, when the initial focus on nursing home vaccinations becomes less relevant over time, will be examined in the following section. Thus, some of the negative efficiency effects of a state's direct involvement are countered by nursing homes and overall health employment.

As in Table 2 with regard to vaccine administration, states with elderly populations and with Democrat governors were no different from others with regard to vaccination efficiency.

\subsection{Robustness checks using alternative timing of vaccine rollouts}

As the information on vaccine rollouts is coming out with regularity, we conducted a robustness check by measuring the two dependent variables at an alternative date February 2, 2021. Besides checking for robustness at an alternative time period where states had greater experience in confronting the challenges faced by the vaccine rollout, the second date also accounts for a change in the government ideology with a change in the presidency and the balance of power at the federal level and in states across the Union.

The corresponding results, using variants of Tables 2 and 3, are reported in Table 4. Overall, we find that the results for the latter period are mixed, with some support for earlier findings and some remarkable differences. 
Table 3 Drivers of COVID-19 Vaccination Delivery Efficiency (Jan. 12, 2021). Outcome measure: Percent of Distributed Vaccines Administered [VACeff]

\begin{tabular}{|c|c|c|c|c|}
\hline Model $\rightarrow$ & 2.1 & 2.2 & 2.3 & 2.4 \\
\hline $\begin{array}{l}\text { Real GDP per capita } \\
\text { [RGDPpc] }\end{array}$ & $\begin{array}{l}0.016^{* *} \\
(2.1)\end{array}$ & $\begin{array}{l}0.014 \\
(1.6)\end{array}$ & $\begin{array}{l}0.014^{* *} \\
(2.2)\end{array}$ & $\begin{array}{l}0.008 \\
(0.9)\end{array}$ \\
\hline $\begin{array}{l}\text { State population } \\
{[\mathrm{POP}]}\end{array}$ & $\begin{array}{l}-0.110 \\
(1.5)\end{array}$ & $\begin{array}{l}-0.119 \\
(1.4)\end{array}$ & $\begin{array}{l}-0.116 \\
(1.5)\end{array}$ & $\begin{array}{l}-0.125^{*} \\
(1.8)\end{array}$ \\
\hline $\begin{array}{l}\text { Rural population } \\
\text { [RURAL] }\end{array}$ & $\begin{array}{l}0.009 \\
(1.5)\end{array}$ & $\begin{array}{l}0.009 \\
(1.5)\end{array}$ & $\begin{array}{l}0.005 \\
(0.9)\end{array}$ & $\begin{array}{l}0.003 \\
(0.5)\end{array}$ \\
\hline $\begin{array}{l}\text { Population over } 65 \\
\text { [65plus] }\end{array}$ & $\begin{array}{l}0.040 \\
(0.9)\end{array}$ & $\begin{array}{l}0.030 \\
(0.6)\end{array}$ & $\begin{array}{l}0.050 \\
(1.2)\end{array}$ & $\begin{array}{l}0.012 \\
(0.3)\end{array}$ \\
\hline $\begin{array}{l}\text { Democrat Governor } \\
\text { [Governor] }\end{array}$ & $\begin{array}{l}-0.058 \\
(0.5)\end{array}$ & $\begin{array}{l}-0.055 \\
(0.5)\end{array}$ & $\begin{array}{l}-0.037 \\
(0.3)\end{array}$ & $\begin{array}{l}-0.107 \\
(0.9)\end{array}$ \\
\hline $\begin{array}{l}\text { COVID-19 deaths } \\
\text { [cDEATHS)] }\end{array}$ & $\begin{array}{l}0.003^{* *} \\
(2.6)\end{array}$ & $\begin{array}{l}0.003^{* *} \\
(2.2)\end{array}$ & $\begin{array}{l}0.002^{* *} \\
(2.0)\end{array}$ & $\begin{array}{l}0.002^{*} \\
(1.7)\end{array}$ \\
\hline $\begin{array}{l}\text { Registered nurses } \\
\text { [NURSES] }\end{array}$ & & $\begin{array}{l}-0.000 \\
(0.1)\end{array}$ & & \\
\hline $\begin{array}{l}\text { Physicians } \\
\text { [PHYSICIANS] }\end{array}$ & & $\begin{array}{l}0.001 \\
(0.5)\end{array}$ & & \\
\hline State spending on health and hospitals [SlhHOSP] & & & $\begin{array}{l}-0.0003^{* *} \\
(3.4)\end{array}$ & \\
\hline Centralized public health [CENTRALIZED] & & & $\begin{array}{l}-0.347^{* *} \\
(2.5)\end{array}$ & \\
\hline $\begin{array}{l}\text { Nursing homes } \\
\text { [nHOMES] }\end{array}$ & & & $\begin{array}{l}0.051^{* *} \\
(2.4)\end{array}$ & \\
\hline $\begin{array}{l}\text { Health care workers } \\
\text { [HEALTHworkers] }\end{array}$ & & & & $\begin{array}{l}0.0002^{* *} \\
(2.2)\end{array}$ \\
\hline Observations & 50 & 49 & 50 & 50 \\
\hline Wald $\chi^{2}$ & $14.45^{* *}$ & $17.11^{* *}$ & $57.86^{* *}$ & $21.36^{* *}$ \\
\hline Pseudo R-square & 0.01 & 0.01 & 0.02 & 0.01 \\
\hline
\end{tabular}

See Table 1 for variable details. All models include a constant term in these fractional response regressions assuming a logit distribution. Dependent variable converted into [0,1] fraction prior to estimation. The numbers in parentheses are (absolute value) z-statistics. Vaccine data are for January 12, 2021

* denotes statistical significance at the $10 \%$-level, and ** denotes significance at the $5 \%$-level (or better)

First, more prosperous states continued to see vaccine administration gains, but now such states had no efficiency advantages. Quantitatively, the elasticity of VACadmin with respect to RGDPpc is almost half in the latter period compared to the former period (specifically, 0.4 in Model 1.1A, compared to 0.8 in Model 1.1). Qualitatively similar was the case for more rural states (although the coefficient on RURAL is marginally significant in Model 2.3A).

Second, less populous states showed greater administration and efficiency than larger states. While the results for vaccine administration support earlier findings, those with efficiency now are stronger than the earlier period. On the other hand, the effects of COVID-19-related deaths on efficiency are not evident in the latter period. 
Table 4 Drivers of COVID-19 Vaccination Administration and Delivery Efficiency (Feb. 2, 2021)

\begin{tabular}{|c|c|c|c|c|}
\hline \multirow{2}{*}{$\begin{array}{l}\text { Model } \rightarrow \\
\text { Outcome measure } \rightarrow\end{array}$} & $1.1 \mathrm{~A}$ & $1.3 \mathrm{~A}$ & $2.1 \mathrm{~A}$ & $2.3 \mathrm{~A}$ \\
\hline & \multicolumn{2}{|c|}{$\begin{array}{l}\text { Vaccines Administered per } \\
\text { 100k population [VACadmin] }\end{array}$} & \multicolumn{2}{|c|}{$\begin{array}{l}\text { Percent of Vaccines } \\
\text { Administered [VACeff] }\end{array}$} \\
\hline $\begin{array}{l}\text { Real GDP per capita } \\
\text { [RGDPpc] }\end{array}$ & $\begin{array}{l}70.28^{* *} \\
(2.5)\end{array}$ & $\begin{array}{l}85.98^{* *} \\
(3.0)\end{array}$ & $\begin{array}{l}0.007 \\
(1.4)\end{array}$ & $\begin{array}{l}0.009 \\
(1.4)\end{array}$ \\
\hline $\begin{array}{l}\text { State population } \\
{[\mathrm{POP}]}\end{array}$ & $\begin{array}{l}-630.76^{* *} \\
(2.5)\end{array}$ & $\begin{array}{l}-702.00^{* *} \\
(2.2)\end{array}$ & $\begin{array}{l}-0.090^{*} \\
(1.7)\end{array}$ & $\begin{array}{l}-0.109^{* *} \\
(2.0)\end{array}$ \\
\hline $\begin{array}{l}\text { Rural population } \\
\text { [RURAL] }\end{array}$ & $\begin{array}{l}37.39^{* *} \\
(2.1)\end{array}$ & $\begin{array}{l}68.37^{* *} \\
(3.1)\end{array}$ & $\begin{array}{l}0.006 \\
(1.3)\end{array}$ & $\begin{array}{l}0.009^{*} \\
(1.9)\end{array}$ \\
\hline $\begin{array}{l}\text { Population over } 65 \\
\text { [65plus] }\end{array}$ & $\begin{array}{l}0.19 \\
(0.0)\end{array}$ & $\begin{array}{l}-1.36 \\
(0.0)\end{array}$ & $\begin{array}{l}-0.007 \\
(0.2)\end{array}$ & $\begin{array}{l}-0.002 \\
(0.1)\end{array}$ \\
\hline $\begin{array}{l}\text { Democrat Governor } \\
\text { [Governor] }\end{array}$ & $\begin{array}{l}263.96 \\
(0.6)\end{array}$ & $\begin{array}{l}172.15 \\
(0.4)\end{array}$ & $\begin{array}{l}0.058 \\
(0.8)\end{array}$ & $\begin{array}{l}0.042 \\
(0.5)\end{array}$ \\
\hline $\begin{array}{l}\text { COVID-19 deaths } \\
\text { [cDEATHS })]\end{array}$ & $\begin{array}{l}-1.65 \\
(0.4)\end{array}$ & $\begin{array}{l}2.42 \\
(0.7)\end{array}$ & $\begin{array}{l}0.001 \\
(0.9)\end{array}$ & $\begin{array}{l}0.001 \\
(1.4)\end{array}$ \\
\hline State spending on health and hospitals [SlhHOSP] & & $\begin{array}{l}-0.886^{* *} \\
(2.7)\end{array}$ & & $\begin{array}{l}-0.0001 \\
(1.0)\end{array}$ \\
\hline Centralized public health [CENTRALIZED] & & $\begin{array}{l}-307.02 \\
(0.5)\end{array}$ & & $\begin{array}{l}-0.110 \\
(1.1)\end{array}$ \\
\hline $\begin{array}{l}\text { Nursing homes } \\
\text { [nHOMES] }\end{array}$ & & $\begin{array}{l}-249.86^{* *} \\
(2.4)\end{array}$ & & $\begin{array}{l}-0.028 \\
(1.5)\end{array}$ \\
\hline Observations & 50 & 50 & 50 & 50 \\
\hline F-statistic/Wald $\chi^{2}$ & $3.89^{* *}$ & $3.35^{* *}$ & $15.81^{* *}$ & $14.61^{*}$ \\
\hline R-square/Pseudo R-square & 0.35 & 0.47 & 0.003 & 0.004 \\
\hline
\end{tabular}

See Table 1 for variable details. All models include a constant term. Models 1.1A and 1.3A are estimated via ordinary least squares. Models 2.1A and 2.3A are estimated using fractional response regressions assuming a logit distribution. Dependent variable converted into $[0,1]$ fraction prior to estimation. The numbers in parentheses in all models are robust (absolute value) t-statistics/z-statistics. Vaccine data are for February 2, 2021

* denotes statistical significance at the $10 \%$-level, and ** denotes significance at the $5 \%$-level (or better)

Third, and perhaps most striking, are the results with respect to the medical variables. All three, SlhHOSP, CENTRALIZED, and nHOMES, had no impact on vaccine efficiency, while the negative sign on SlhHOSP supported earlier results with regard to vaccine administration. Further, the negative impact of nursing homes on vaccine administrations is likely due to nearly all states broadening the priority for vaccinations and most nursing home populations already being vaccinated in the United States. ${ }^{16}$

Finally, as shown in Tables 2 and 3, the influences of Democrat governors and elderly populations continue to be statistically insignificant. ${ }^{17}$

\footnotetext{
$\overline{16} \mathrm{https} / /$ www.cdc.gov/coronavirus/2019-ncov/vaccines/index.html.

${ }^{17}$ Some wealthier elderly might be engaging in vaccine tourism and that might have something to do with the insignificance of the resulting coefficient (https://www.theguardian.com/us-news/2021/jan/31/us-vaccinetourism-state-borders-covid-19-shots).
} 
Whereas the data on vaccination success will emerge over time, this study provides intermediate information when there is still time to fine-tune the vaccination process, with positive implications for avoiding unnecessary loss of life.

\subsection{Impact of a legacy of corruption}

The corruption risks associated with all phases of the COVID-19 vaccine rollout, from manufacture to allocation and distribution, have been well recognized by international bodies (United Nations Office on Drugs and Crime [21]). ${ }^{18}$ In the present context, state corruption can potentially have an impact on vaccinations, with the effects being either positive or negative, depending upon whether enabling or retarding effects of corrupt activity prevail (see Goel et al. [13]). Since U.S. corruption is hard to detect, especially concurrently, we consider two measures of state-level corruption lagged over two different time periods: (a) CorruptSR: a five-year average of per-capita federal corruption convictions in a state; and (b) CorruptLR: a corresponding 10-year average (see Table 1 for details). Goel et al. [13] have discussed how the tension between the scale and speed of vaccine roll out might interject with corruption.

Key questions addressed in this respect are:

- What are the effects of corruption legacy on vaccination administration and efficiency?

- Are the effects of short-run and long-run corruption alike?

These results, inserting the two corruption variables alternatively into Models from Table 2-4, are reported in Table 5. Since most of the other findings are in broad agreement with earlier results, we will focus on the corruption variables.

Overall, the impact of corruption is consistent with the greasing theory - states with a greater legacy of corruption seem relatively better adept at vaccination administration and efficiency. This might have to do with weak institutions in such states, where strict vaccination mandates (e.g., who to vaccinate on priority, how to ship vaccines and at what temperatures, policing, etc.) better enable administration and efficiency of vaccines. Furthermore, the presence of corruption might increase vaccinations when clinics are open longer/special hours, or allow the jumping of queues via the payment of bribes. It could also be the case that more corrupt states are better able to inflate vaccination success data to show better performance.

We do, however, find differences in the impact of corruption, especially those of CorruptSR, across vaccines administration and vaccine efficiency - with VACeff positively and significantly impacted by a greater corruption legacy (albeit at the 10\%-level in Model 3.3a). Viewed differently, in the latter vaccination period (data from February 2, 2021), short-term corruption legacy significantly and positively impacts vaccination efficiency, but not administration.

Relatively speaking, the effects of short-term corruption are stronger than longerterm corruption - effects of corruption tend to dissipate over time. Thus, the answer to

\footnotetext{
${ }^{18}$ As a recent example in the US regarding vaccine distribution, see "Coming to a black market near you: Covid-19 vaccine." https:/www.nbcnews.com/news/us-news/coming-black-market-near-you-covid-19vaccine-n1253504.
} 
Table 5 Drivers of COVID-19 Vaccination Administration and Delivery Efficiency: Impact of legacy of corruption

\begin{tabular}{|c|c|c|c|c|c|c|c|c|}
\hline \multirow{2}{*}{$\begin{array}{l}\text { Model } \rightarrow \\
\text { Outcome measure } \rightarrow\end{array}$} & $3.1 \mathrm{a}$ & $3.2 \mathrm{a}$ & $3.1 \mathrm{~b}$ & $3.2 b$ & $3.3 \mathrm{a}$ & $3.4 \mathrm{a}$ & $3.3 b$ & $3.4 \mathrm{~b}$ \\
\hline & \multicolumn{4}{|c|}{$\begin{array}{l}\text { Vaccines Administered per } 100 \mathrm{k} \text { population } \\
\text { [VACadmin] }\end{array}$} & \multicolumn{4}{|c|}{$\begin{array}{l}\text { Percent of Vaccines Administered } \\
\text { [VACeff] }\end{array}$} \\
\hline \multirow{2}{*}{$\begin{array}{l}\text { Period } \rightarrow \\
\text { Real GDP per capita } \\
\text { [RGDPpc] }\end{array}$} & \multicolumn{2}{|c|}{ Jan. 12, 2021} & \multicolumn{2}{|c|}{ Feb. 2, 2021} & \multicolumn{2}{|c|}{ Jan. 12, 2021} & \multicolumn{2}{|c|}{ Feb. 2, 2021} \\
\hline & $\begin{array}{l}44.33^{* *} \\
(3.4)\end{array}$ & $\begin{array}{l}45.08^{* *} \\
(3.4)\end{array}$ & $\begin{array}{l}72.05^{* *} \\
(2.6)\end{array}$ & $\begin{array}{l}73.90^{* *} \\
(2.6)\end{array}$ & $\begin{array}{l}0.02^{* *} \\
(2.2)\end{array}$ & $\begin{array}{l}0.02^{* *} \\
(2.2)\end{array}$ & $\begin{array}{l}0.01 \\
(1.5)\end{array}$ & $\begin{array}{l}0.01 \\
(1.4)\end{array}$ \\
\hline $\begin{array}{l}\text { State Population } \\
{[\mathrm{POP}]}\end{array}$ & $\begin{array}{l}-349.56^{* *} \\
(2.5)\end{array}$ & $\begin{array}{l}-340.52^{* *} \\
(2.5)\end{array}$ & $\begin{array}{l}-626.73^{* *} \\
(2.5)\end{array}$ & $\begin{array}{l}-611.78^{* *} \\
(2.4)\end{array}$ & $\begin{array}{l}-0.11 \\
(1.4)\end{array}$ & $\begin{array}{l}-0.11 \\
(1.4)\end{array}$ & $\begin{array}{l}-0.09^{*} \\
(1.8)\end{array}$ & $\begin{array}{l}-0.09^{*} \\
(1.7)\end{array}$ \\
\hline $\begin{array}{l}\text { Rural population } \\
\text { [RURAL] }\end{array}$ & $\begin{array}{l}19.81^{*} \\
(1.8)\end{array}$ & $\begin{array}{l}18.77^{*} \\
(1.7)\end{array}$ & $\begin{array}{l}34.55^{*} \\
(1.9)\end{array}$ & $\begin{array}{l}31.80^{*} \\
(1.8)\end{array}$ & & $\begin{array}{l}0.01 \\
(1.3)\end{array}$ & $\begin{array}{l}0.01 \\
(1.1)\end{array}$ & $\begin{array}{l}0.01 \\
(1.1)\end{array}$ \\
\hline $\begin{array}{l}\text { Population over } 65 \\
\text { [65plus] }\end{array}$ & $\begin{array}{l}37.46 \\
(0.5)\end{array}$ & $\begin{array}{l}47.87 \\
(0.6)\end{array}$ & $\begin{array}{l}-4.81 \\
(0.0)\end{array}$ & $\begin{array}{l}8.31 \\
(0.1)\end{array}$ & $\begin{array}{l}0.04 \\
(0.9)\end{array}$ & $\begin{array}{l}0.04 \\
(0.9)\end{array}$ & $\begin{array}{l}-0.01 \\
(0.3)\end{array}$ & $\begin{array}{l}-0.01 \\
(0.2)\end{array}$ \\
\hline $\begin{array}{l}\text { Democrat Governor } \\
\text { [Governor] }\end{array}$ & $\begin{array}{l}-96.17 \\
(0.4)\end{array}$ & $\begin{array}{l}-112.13 \\
(0.5)\end{array}$ & $\begin{array}{l}330.96 \\
(0.7)\end{array}$ & $\begin{array}{l}336.01 \\
(0.7)\end{array}$ & $\begin{array}{l}-0.04 \\
(0.3)\end{array}$ & $\begin{array}{l}-0.05 \\
(0.4)\end{array}$ & $\begin{array}{l}0.08 \\
(1.0)\end{array}$ & $\begin{array}{l}0.07 \\
(0.9)\end{array}$ \\
\hline $\begin{array}{l}\text { COVID-19 deaths } \\
\text { [cDEATHS)] }\end{array}$ & $\begin{array}{l}0.77 \\
(0.3)\end{array}$ & $\begin{array}{l}0.49 \\
(0.2)\end{array}$ & $\begin{array}{l}-2.79 \\
(0.6)\end{array}$ & & $\begin{array}{l}0.003^{* *} \\
(2.1)\end{array}$ & $\begin{array}{l}0.003^{* *} \\
(2.1)\end{array}$ & $\begin{array}{l}0.00 \\
(0.4)\end{array}$ & $\begin{array}{l}0.00 \\
(0.5)\end{array}$ \\
\hline $\begin{array}{l}\text { Corruption - 5-year } \\
\text { avg. [CorruptSR] }\end{array}$ & $\begin{array}{l}885.05^{*} \\
(1.8)\end{array}$ & & $\begin{array}{l}909.77 \\
(1.0)\end{array}$ & & $\begin{array}{l}0.30^{*} \\
(1.8)\end{array}$ & & $\begin{array}{l}0.30^{* *} \\
(2.3)\end{array}$ & \\
\hline $\begin{array}{c}\text { Corruption - 10-year } \\
\text { avg. [CorruptLR] }\end{array}$ & & $\begin{array}{l}1048.64^{*} \\
(2.0)\end{array}$ & & $\begin{array}{l}1535.34 \\
(1.3)\end{array}$ & & $\begin{array}{l}0.26 \\
(1.0)\end{array}$ & & $\begin{array}{l}0.23 \\
(1.1)\end{array}$ \\
\hline Observations & 50 & 50 & 50 & 50 & 50 & 50 & 50 & 50 \\
\hline F-statistic/Wald $\chi^{2}$ & $4.53^{* *}$ & $4.09^{* *}$ & $3.38^{* *}$ & $3.32^{* *}$ & $28.73^{* *}$ & $19.20^{* *}$ & $22.53^{* *}$ & $15.58^{* *}$ \\
\hline R-sq./ Pseudo R-sq. & 0.44 & 0.44 & 0.36 & 0.37 & 0.01 & 0.01 & 0.004 & 0.004 \\
\hline
\end{tabular}

See Table 1 for variable details. All models include a constant term. Models with VACadmin as the dependent variable are estimated via ordinary least squares. Models with VACeff as the dependent variable are estimated using fractional response regressions assuming a logit distribution. Dependent variable converted into $[0,1]$ fraction prior to estimation. The numbers in parentheses in all models are robust (absolute value) t-statistics/zstatistics. Vaccine data are for February 2, 2021

* denotes statistical significance at the $10 \%$-level, and ** denotes significance at the $5 \%$-level (or better)

the second question posed above is a no. Quantitatively, comparing Models 3.1a and $3.2 \mathrm{a}$, the elasticity of VACadmin with respect to CorruptSR is somewhat smaller than that with respect to CorruptLR (0.08 versus 0.10$)$, respectively (both based on vaccination data from January 12, 2021). It would be interesting to see how these findings change as data on concurrent corruption emerges.

\section{Concluding remarks}

The scale and gravity of the coronavirus have caused alarm and health anxieties worldwide. These concerns resulted in the push by various governments and the private sector to rapidly develop a successful vaccine. As a result, a number of vaccines have been approved, with many more in various stages of development. Now the focus has partly shifted to rapid and 
equitable public dissemination of the scarce vaccines. Given the disparities in the administration of vaccines (see Fig. 1) and reports of wastage, an understanding of the factors driving the spread and efficiency of these vaccines seems in order.

This paper formally contributes to the examination of the success of efforts to combat the COVID-19 pandemic by studying the drivers of the administration and delivery efficiency of coronavirus vaccines. For this purpose, we use recent data from the 50 US states and place the analysis in the context of socio-economic drivers of vaccinations.

Besides adding insights into the effective use of public resources, an understanding of the challenges faced by a large-scale vaccination rollout would also help the timeline towards achieving herd immunity in the fight against the current COVID-19 pandemic. Our research offers some important insights from the perspective of a developed economy.

Results show that state-economic prosperity and rural population aid vaccine administration and delivery efficiency. More prosperous states have greater resources and better infrastructure to vaccinate their populations, ceteris paribus. Our estimates show that a $10 \%$ increase in per-capita state GDP would increase vaccinations per capita by about $9 \%$. It remains to be seen, however, whether improvements over time in the supply chain, and with the approval of additional vaccine candidates, would preserve or dissipate the advantages of wealthier states.

Delivery efficiency improves in states with more nursing homes per capita, in states with more COVID-19 deaths, and with more health workers. However, the advantage of states with more nursing homes should dissipate after the initial goal of prioritizing nursing home residents is largely achieved. A subset of health workers, including physicians and nurses, did not significantly impact administration or efficiency. A part of this insignificance might be attributed to the fact that these health professionals are bound by the CDC and state guidelines pertaining to vaccinations. On the other hand, vaccination efficiency was lower in states with a centralized public health agency. This might have to do with coordination issues, especially when people in line for vaccinations fail to show up and centralized guidelines about how to avoid vaccines from being wasted might not be as effective as local insights into how to get the vaccinations fast to those in the second or waiting tier. Finally, states with a larger share of the elderly population and those with Democrats as governors were no different from others with regard to vaccinations.

Robustness checks are performed using vaccination from a more recent period. They show some differences in the impacts of drivers of both vaccinations and related efficiency. Finally, a state's legacy of corrupt activity, across two different time dimensions, is broadly consistent with the greasing effects of corruption.

From a policy angle, some of the significant drivers of vaccinations identified in this research, e.g., state population, rural population and even state prosperity, change slowly over time and are not amenable to short-term policy manipulations. With respect to the others, such as health sector employment and spending, while more amenable to policy changes, any recommendations would need to be tempered by the fact that they would be based on fast-changing underlying (especially vaccinations) data. On the other hand, political compulsions in states with high COVID cases might force policymakers to change strategies to combat the pandemic. It is nevertheless our hope that this work provides some initial analytical insights into an important area. Future work with the benefit of additional data, both within the US context and elsewhere, can be expected to further enlighten us. 
Supplementary Information The online version contains supplementary material available at https://doi. org/10.1007/s11066-021-09148-w.

\section{References}

1. Alfano, V., \& Ercolano, S. (2020). The efficacy of lockdown against COVID-19: A cross-country panel analysis. Applied Health Economics and Health Policy, 18, 509-517. https://doi.org/10.1007/s40258020-00596-3.

2. Asongu, S. A., Diop, S., \& Nnanna, J. (2020). The geography of the effectiveness and consequences of Covid-19 measures: Global evidence. Journal of Public Affairs. https://doi.org/10.1002/pa.2483.

3. Baldwin, R., \& Weder di Mauro, B. (Eds.). (2020). Economics in the time of COVID-19. Centre for Economic Policy Research. CEPR Press.

4. Bartolini, D., \& Santolini, R. (2017). Political institutions behind good governance. Economic Systems, 41(1), 68-85.

5. British Medical Journal. (2020). Covid-19: politicisation, "corruption," and suppression of science. BMJ, 371. https://doi.org/10.1136/bmj.m4425.

6. Chabner, B. A. (2020). The corruption of science. Oncologist, 25(11), 907-908. https://doi.org/10.1002/ onco.13549.

7. Farzanegan, M.R., Feizi, M., Gholipour, H.F., 2020. Globalization and outbreak of COVID-19: An empirical analysis, CESifo working paper \#8315, May.

8. Glaeser, E. L., \& Saks, R. E. (2006). Corruption in America. Journal of Public Economics, 90(6-7), 1053-1072.

9. Goel, R. K. (2009). Technological complementarities, demand, and market power. Netnomics, 10, 161170. https://doi.org/10.1007/s11066-009-9034-5.

10. Goel, R. K., Mazhar, U., \& Saunoris, J. W. (2020). Identifying the corrupt cog in the wheel: Dimensions of supply chain logistics and cross-country corruption. Australian Economic Papers. https://doi.org/10. 1111/1467-8454.12226.

11. Goel, R. K., \& Nelson, M. A. (2011). Measures of corruption and determinants of US corruption. Economics of Governance, 12(2), 155-176.

12. Goel, R. K., \& Nelson, M. A. (2021). COVID-19 internet vaccination information and vaccine administration: Evidence from the United States. Journal of Economics and Finance. https://doi.org/10.1007/ s12197-021-09551-x.

13. Goel, R. K., Nelson, M. A., \& Goel, V. Y. (2021). COVID-19 vaccine rollout - scale and speed carry different implications for corruption. Journal of Policy Modeling. https://doi.org/10.1016/j.jpolmod. 2021.04.003.

14. Papke, L. E., \& Wooldridge, J. M. (1996). Econometric methods for fractional response variables with an application to 401(k) plan participation rates. Journal of Applied Econometrics, 11(6), 619-632.

15. Persad, G., Peek, M. E., \& Emanuel, E. J. (2020). Fairly prioritizing groups for access to COVID-19 vaccines. JAMA, 324(16), 1601-1602. https://doi.org/10.1001/jama.2020.18513.

16. Potrafke, N. (2018). Government ideology and economic policy-making in the United States-A survey. Public Choice, 174, 145-207.

17. Price, G., \& van Holm, E. (2021). The effect of social distancing on the early spread of the novel coronavirus. Social Science Quarterly. https://doi.org/10.1111/ssqu.12988.

18. Roccato. M., Russo, S., Colloca, P., \& Cavazza, N. (2021). The lasting effects of the COVID-19 pandemic on support for anti-democratic political systems: A six-month longitudinal study. Social Science Quarterly. https://doi.org/10.1111/ssqu.12958.

19. Salvatore, D., Constantiello, A., \& Campano, F. (2021). Implications of U.S. trade policies after the 2020 pandemic. Journal of Policy Modeling. https://doi.org/10.1016/j.jpolmod.2021.02.012.

20. Turnbull, G. K., \& Djoundourian, S. S. (1993). Overlapping jurisdictions: Substitutes or complements? Public Choice, 75(3), 231-245.

21. United Nations Office on Drugs and Crime (UNODC), 2020. Covid-19 Vaccines and Corruption Risks: Preventing Corruption in the Manufacture, Allocation and Distribution of Vaccines. https://www.unodc. org/documents/corruption/COVID-19/Policy paper_on_COVID-19_vaccines_and_corruption_risks.pdf

22. Wooldridge, J. M. (2010). Econometric analysis of cross section and panel $\bar{d}$ ata (2nd ed.). MIT Press. 